\title{
The Classroom Interaction Patterns in Bilingual Classroom at Junior High School in Medan City
}

Meisuri1 $^{1,2 *}$, T. Silvana Sinar ${ }^{1}$, Busmin Gurning $^{2}$, T. Tyrhaya Zein ${ }^{1}$

${ }^{1}$ Universitas Sumatra Utara, Indonesia

${ }^{2}$ Universitas Negeri medan, Indonesia

Corresponding Author: Meisuri, E-mail: meisuriw@yahoo.com

\begin{tabular}{l} 
ARTICLE INFO \\
\hline Article history \\
Received: March 10, 2018 \\
Accepted: May 16, 2018 \\
Published: August 31, 2018 \\
Volume: 9 Issue: 4 \\
Advance access: July 2018 \\
\hline Conflicts of interest: None \\
Funding: None \\
\hline
\end{tabular}

\section{Key words:}

Classroom Interaction Patterns, Bilingual Class,

FIAC Model

\begin{abstract}
This paper deals with the interaction pattern between teacher and students in the real classroom lessons. This study was primarily conducted to determine the patterns of classroom interaction produced by the teachers and learners during the class sessions in the bilingual middle-school classrooms in Medan City, Indonesia. The data were spoken texts of teachers from five videorecorded classes (Mathematics, Physics, Biology, English and IT/TIK) during the period of even semester, and were then analyzed by applying the Flanders Interaction Analysis Categories System (FIACS) 'Interaction Model' following the frame works proposed by Flanders (1970). From the data analysis, it was found that the talk was dominated by teachers, particularly on the categories of no 4,5 , and 6 , while students practiced no 8 mostly, and it also indicated that instructor expressions were very overwhelming in each example of assignments amid the class sessions, while understudies reactions or different properties were moderately low in rates in an educator centered classroom aside from in the scene no. 5 (IT Lesson) where understudies took the greater part of the cooperation among peers. The examination likewise demonstrates that elicitation, reaction, and input were deliberately utilized by instructor, and understudies were a piece of the structure of classroom talk exercises. The example, notwithstanding, could be changed relying upon the educator expectation or the times of lesson that understudies learn.
\end{abstract}

\section{INTRODUCTION}

In this worldwide period, English, as the world dialect for universal correspondence and science, has been utilized for correspondence in numerous nations. Graddol (2001) and Dough puncher (2003) additionally affirm that English as a global dialect is utilized to convey, to reinforce and to secure relationship among all nations on the planet and in all parts of life, for instance in tourism, business, legislative issues, science, and innovation. Individuals from non-English talking nations, in this manner, consider that it is ending up increasingly imperative to learn English either as a moment or a remote dialect. Regardless of a developing mindfulness that primary language (MT) training is more powerful than bilingual or second dialect medium of guideline (Heugh, 2002: 171; Rademeyer, 2005:7), English as a moment dialect has turned into the overwhelming medium of direction in bilingual classes in Medan City, North Sumatra Indonesia. It is an extraordinary class program planned for Junior and Senior Secondary Schools in which five subjects (Arithmetic, Material science, Science, IT/TIK, and English) are conveyed to the understudies by utilizing English as the medium of guideline, with the expectation that this program could enhance the instructive quality which will thusly impost the qualified and focused HR to confront worldwide world.
The flow of instructing is an essential factor in how much understudies learn (Liu and Elicker, 2013; Grouws, 1981). Despite the fact that understudies' execution may not be a straightforward direct outcome of the educators' showing demonstration, the last has a great deal to do with classroom learning. Instructors build up the example of general lead amid a lesson, while on their part understudies likewise set up specific kinds of conduct to match with this example (Meisuri, 2006, 2014). Thusly the understudies take part to fluctuating degrees in various classes and respond distinctively to various educators. This joined instructional example and understudy investment prompt a particular classroom condition portrayed by particular cooperation designs.

Instructor and understudy cooperation is comprehended to be a critical issue in training, and advantageous for understudies' learning. Flanders (1970) built up a diagnostic framework for instructor understudy collaboration and recognized seven classifications of educators' practices clearing up sentiments, commending, utilizing understudies' thoughts, making inquiries, addressing, giving headings, and condemning. Button (2006) shows that instructors could build up understudies' thoughts by making inquiries. Kalu (2003) found that when educators made particular inquiries or requested understudies' assistance, youngsters felt more 
sure and secure. Two parts can be recognized among instructors and understudies: parallel and slant. Whenever instructors and understudies perform parallel parts, they have level with status (Zhi and Feng, 2013). Whenever instructors and understudies perform slant parts, they cooperate as teachers and the informed (Liu and Elicker, 2013). For instructors, practices, for example, playing with kids and communicating their encounters were identified with the parallel part, and practices, for example, coordinating and making inquiries were identified with the slant part. Amid educator understudy communications, instructors can utilize systems, for example, section, adjustment, and extension to reconceptualize the data gave by the understudies (Fisher and Larkin, 2007). While a couple of studies have explored instructor understudy associations, most past examinations have been led in a classroom setting where one educator was in charge of a few youngsters. Chi, Siler, Jeong, Yamauchi and Hausmann (2001) recommended that in a balanced setting, educators could give reasonable help as indicated by understudies' needs, consequently improving understudies' inspiration and learning execution.

\section{Classroom Interaction}

Interaction happened regular in the classroom exercises between the educator and the students in learning process as channels of understanding its targets. Collaboration generally characterizes as a sort of activity that happens as at least two items has an impact upon each other. This cooperation is typically used to express their thoughts together. Allwright and Breen as cited by Chaudron (1988:10) expressed: Cooperation is seen as huge in light of the fact that it is contended that: lone through communication, the student can disintegrate the TL structures and get importance from classroom occasion and delivers results (Allwright and Bailey, 1991). Waterways (1987) includes that the educator ought not be excessively concentrating on the best strategy, somewhat searching for the most suitable approach, and outline of materials.

Interaction in the classroom is a fundamental piece of showing learning process. Cooperation or human communication has been characterized as a procedure whereby at least two individuals occupied with proportional activities. This activity might be verbal or nonverbal (Mercer, 2010), and should be not quite the same as the general ones. This specific dialect utilized as a part of the classroom or classroom talk can influence different parts of understudy learning in any subject. The instructor may utilize English for the entire collaboration program with the reason that the understudies can enhance their dominance in English (Meisuri, 2005). One reason is that when English is utilized as a platform talk, the understudies are getting used to interface in their day by day exercises utilizing the dialect (Diknas 2004; Meisuri, 2008).

It is by and large acknowledged that educators of English assume a main part in giving students the information, aptitudes and understanding they have to peruse, compose, talk and listen viably (Graddol, 1997). In any case, Goodwyn and Findlay (2003:2 7) bring up that all instructors have a stake in powerful proficiency. Students may neglect to compre- hend scholarly ideas through the dialect they are as yet learning in light of the fact that their subject substance instructors are unequipped for helping them to do as such.

\section{Bilingual Education}

An elective model to customary Training which readies the native of tomorrow with the scholastic, etymological and social abilities that the present current society requires (Mejia, 2002; Meisuri, 2014). A chance to take in a moment dialect and during a time dialect from extremely youthful. The kids will be presented to an English situation at school, tuning in to English constantly, however by no means would they likewise be compelled to talk in English before they are prepared and certain to do as such. They will dependably be urged to utilize English while in school. The model should apply to the setting where the two dialects are being utilized to show all educational modules subjects. So a youngster will think about math, material science, history, and science in both English and his first language (Bialystok, 2001). This arrangement of Bilingual Instruction can't however bolster and create bilingual ability, broadness of brain, energy about different societies, increment openings for work for the future, and mentally help to think all the more adaptably and imaginatively.

This worldwide institutionalized school ends up prominent in instructive issues in Indonesia in accordance with the issue of government direction No. 20 of 2003 on National Instruction Frameworks, stipulated that "Administration as well as neighborhood government complete no less than one training unit in all instructive level to be created into universally standard instruction unit," and began by setting up a bilingual school or the alleged Rintisan Sekolah Berstandard Internasional (RSBI. Toward the end, if the school will turn into a worldwide institutionalized school, every one of the understudies ought to cooperate in the instructing learning process by utilizing English, maybe a couple classes, as well as the entire classes in this school.

\section{Model of Classroom Interaction (FIACS)}

The most essential factors in a classroom circumstance are the collaborations and trades started by educator and understudies. Flanders (1970) initially built up an exploration apparatus, named as Flanders Communication Investigation (FIA). FIA framework comprises of ten classifications of correspondence which are said to be comprehensive of all correspondence conceivable outcomes. Seven classifications are utilized to classify different parts of educator talk and two are utilized to order understudies talk, and additionally to enhance instructor understudy collaboration design.

Examples of Classroom Association at the Diverse Instructive Levels in the Light of Flanders Connection investigation. Imamullah (2008) directed an exploration to investigate examples of classroom communication at optional and tertiary levels in the North West Boondocks Territory of Pakistan utilizing Flanders Connection Examination framework. This examination was noteworthy in light of the fact that its discoveries and conclusions may animate educa- 
tors to enhance their showing conduct keeping in mind the end goal to expand understudies learning.

\section{RESEARCH METHOD}

The study focused on classroom interaction in the seventh and eighth grades of Examplary Bilingual Classes at SMP Negeri 1 Medan North Sumatra, Indonesia in the light of Flanders Interaction Analysis (FIACS). Thus, the intention in the present study was to determine the pattern of classroom interaction in the five different classroom (Mathematics, Biology, Phisics, IT/TIK, and English) taughed by five, 3 male and 2 female teachers by utilizing quantitative content analysis of video recordings and a sequential analysis method to explore teacher-student interaction patterns applied to situations in five different subjects attended by 5 teachers by using the suggested FIAC Model of Flanders in Table 1.

Tabel 1. Flanders' Interaction Analysis Category (FIAC)

The data generated with the instruments were both quantitative and qualitatively analyzed using the 10 category system of Flanders Model. The results of data analysisis are shown in the following figures.

\section{RESULTS AND DISCUSSION}

The analysis contains both the coding and elaborating processes toward the language pattern of classroom interaction. The process of verbal codification of teacher and students interaction was done by applying the Flanders model of Interaction Analysis Category System (FIACS) on the ten categories of 10x10 matrix, Data were grouped into langueage of teacher category (1-7), students category (8-9), and class situation category (10) which were then identified according to the systematic sequencing of pairing interaction between teacher-students, students-teacher or student-student. This technique of analysis will determine both quantitative and qualitative dimentions of data on the teacher and student in-

Table 1. Flanders' interaction analysis category (FIAC)

\begin{tabular}{lccl}
\hline Talks & Move & $\begin{array}{c}\text { Category } \\
\text { number }\end{array}$ & Activities \\
\hline Teacher talk & & 1 & Accept feeling \\
& & 2 & $\begin{array}{l}\text { Praise or } \\
\text { encourages } \\
\text { Accept ideas }\end{array}$ \\
Indirect & Response & 3 & $\begin{array}{l}\text { Asks questions } \\
\text { influence }\end{array}$ \\
Direct & Initiation & 6 & Gives directions \\
influence & & 5 & \\
Pupil talk & Response & 8 & Pupil's response \\
& Initiation & 9 & Students talk/ \\
& & & initiation \\
Silence & & 10 & Silence or confusion \\
\hline
\end{tabular}

teraction during the whole process of teaching and learning in the classroom. Flanders model was, therefore, used to describe the teacher-students verbal interaction in reference to the 10 categories (FIACS).

\section{Data Classification}

Data collected in this study were classified into five subjects representation (Biology, Mathematics, Physics, IT/TIK, and English) of bilingual class in the junior high school.

\section{The analyses of 5 subjects based on the 10 categories of flanders}

Figure 1 shows the interaction between teacher and students in Biology class. It represent balanced distribution of the 10 categories. Teacher explains $(28 \%)$ and students initiation (28\%). Yet, category 10 (crouded class) is significantly high (18\%). The interaction was recorded as the teacher gave information and lectured and interfered by students commmented or asked questions. The discussion shows great success for most students actively participated. The dinamic atmosphere was in respond to the teacher strategy in teaching.

Figure 2 shows the classroom interaction in Mathematics. As it is always assumed that students do not interact much

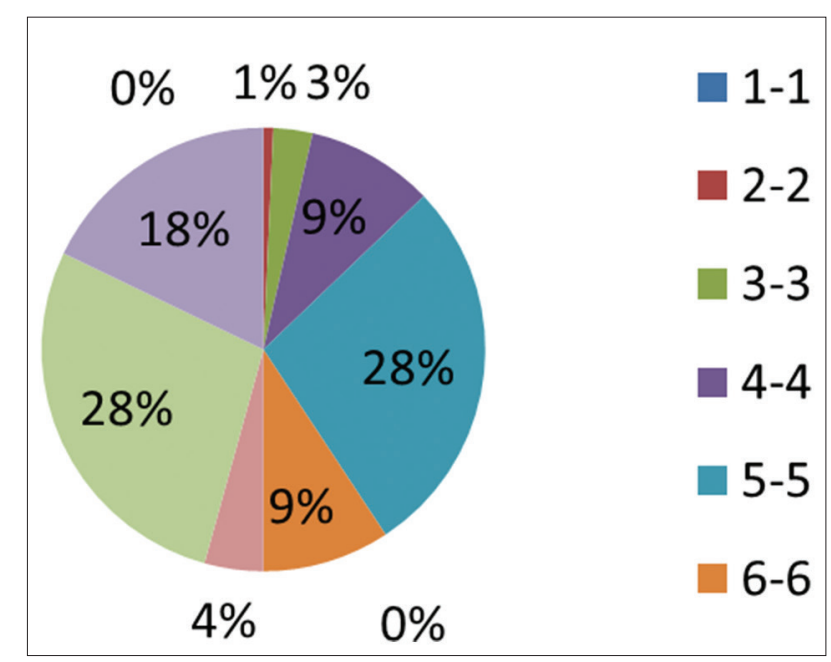

Figure 1. Category distribution in biology class

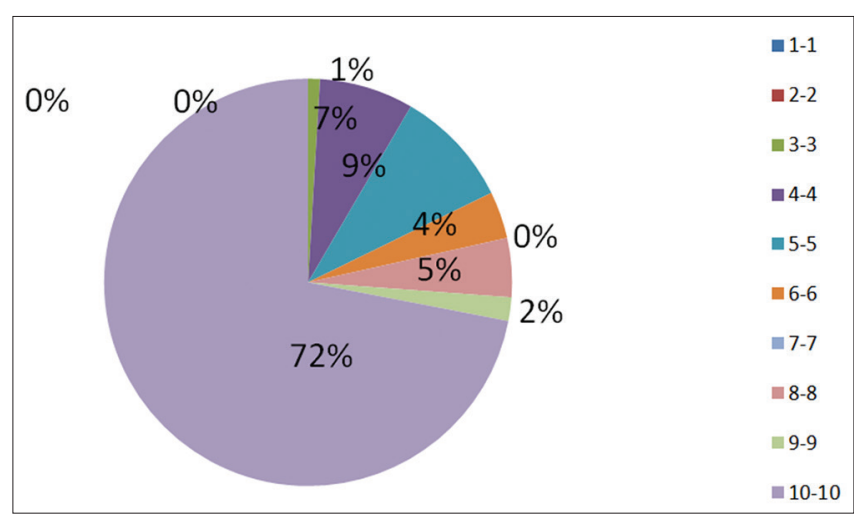

Figure 2. The category distribution in math class 


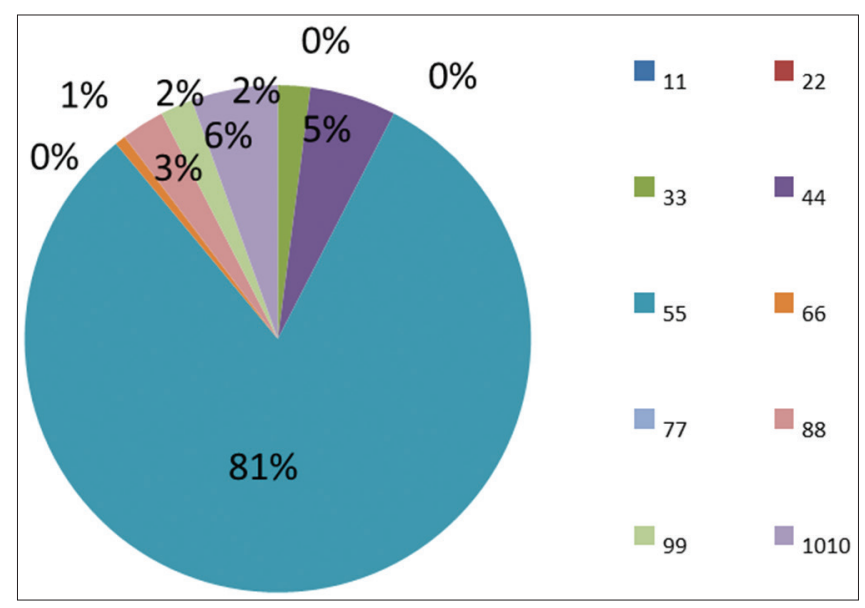

Figure 3. The category distribution in physics class

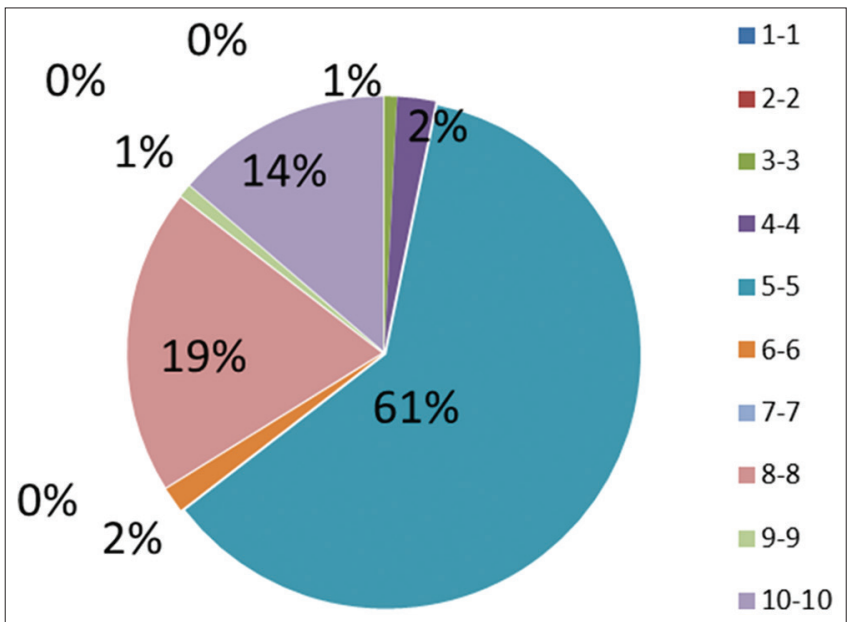

Figure 4. The category distribution in english class

with the teacher, and mostly they do exercise or solve math problems either individually or in group. The class silence takes up very significant point (72\%), followed by category $5,(9 \%)$. This is a common view of science class where students are usually fully absorved with their work in solving mathematics problems.

In Figure 3 teacher is dominanting the class talk (no.5) with a most total off time for teaching and learning process $(81 \%)$ wjch is the followed by silent and crowded class atmospher (13\%), and almost no teacher-student interaction developed $(3 \%)$. It, obviously indicated that teacher took over almost all activitiies in the classroom and almost no interaction developed to establish any social and academic is course to achieve the instructional objectives as it is stipulated in curriculum or syllabus. This type of classroom atmosphere could hardly encourage students to be active and creative learners and is supposed to be transformed into a better learning process.

In Figure 4 English lesson, the use of category 5, (teacher instucts or directs students) dominates the class talk, beside the use of no. 4 (teacher question).and no 8 (students answer). Yet, the session in classical discussion indicated that students were active not only in responding to teacher questions but also in initiating the question and comment, which represent a very significant postion each $(61 \%, 19 \%$,

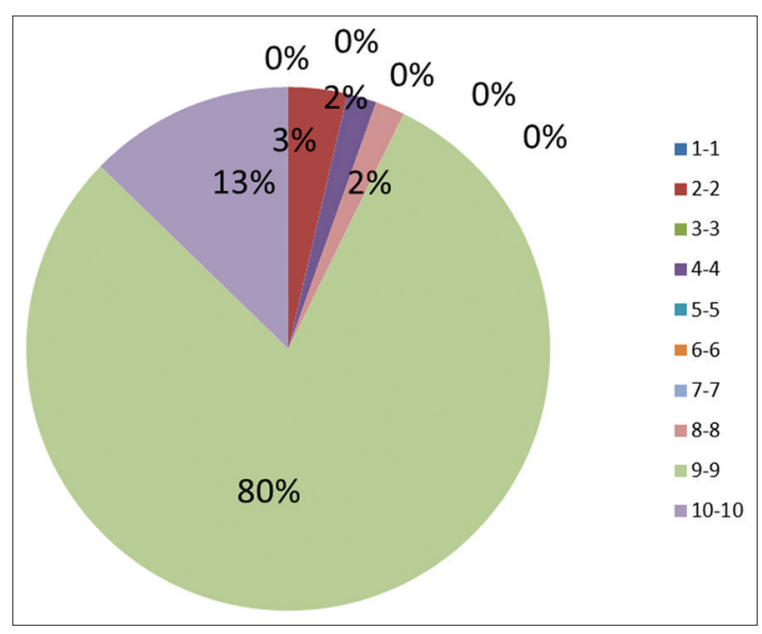

Figure 5. The Category Distribution in IT/TIK Class

and $14 \%$ ). The least category occured (no.10) indicated that the discussion session was well done and enjoyed by the students, and it could be seen from the exchange structure of language used.

In Figure 5 class atmosphere in IT/TIK lesson where students are having presentation as their group assignment. The class scene was significantly different from the previous setting of class situation in which students were almost totally the agents of the learning process. They debeloped a unique exchange of interaction for they represent the roles of teacher in initiating, asking question, and explaing the material. The figure shows that students inisiative (no.9) took a big number in percentage that representing the dominance of students role $(80 \%)$. Despite the crowd situation caused during the discussion sesion, students were actively taking charge of the question-answer session. Not only were they attentive in listening to the presentation but also antusiastic in creating language or discourse as to practice thier English. Both sides, presenter and audiences students enjoyed their class activity.

\section{The comparatively distribution of teacher and students talk in 5 subjects}

To resume the analysis of classroon interaction discourse in all five subjects, it is therefore, necessary to put the actual domain of both teacher and students talk in visual in reference to the FIACS model of Flanders. The classroom interaction, was generally still dominated by teacher, however, this study has proved that there could be possible to have and create a different and a more student-active learning situation. It is showed here by displaying classroom interaction from the bilingual class (English lesson), and also other classes that showed almost even distribution of categories or student dominant category within the learning process (IT/TIK lesson) where activities almost totally cocducted by students and teacher took role as the facilitator, guide, and evaluator, the most intented roles expectedly taken in bilingual program.

The following figures will clearly show either teacher or student dominance in classroom interaction. 


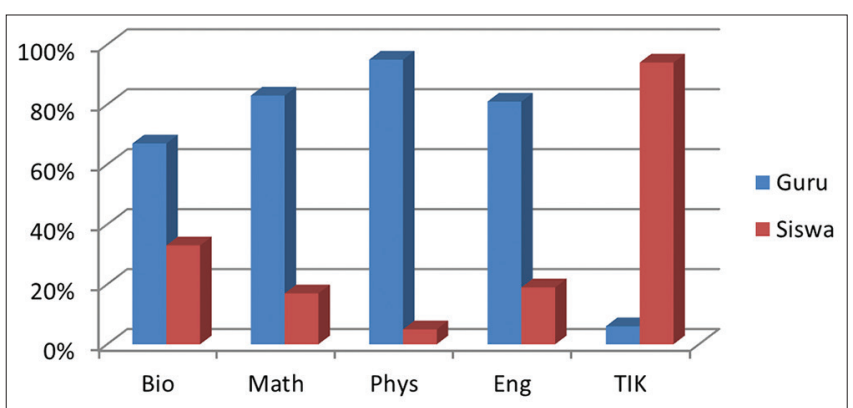

Figure 6. The recapitulation of teacher and students talk in five lessons

Figure 6. shows all five pairs of teacher and students talk in Biology, Mathematics, Physics, English and IT/TIK. In Biology lesson $t$ the teacher talk alone take $67 \%$ of the total interaction in the Biology classroom, while students share $33 \%$ of the session talk. It proves that the many previous findings of teacher dominance in the so-called traditional classrooms are still continue to becoming the most hinder in the teaching and learning process, as to the $2 / 3$ principle of teacherstudent talk ratio. This situation represents the common picture of classroom interaction,particularly in Indonesia, in which teacher spends more times explaining, questiong, criticizing, or repeatning students' aswers. Students roles, however, could ce only categorized into responding and answering teacher's questions that almost reach the onethird of the whole interaction.

Mathematics class represents a very significant percentage of teacher talk $(83 \%)$ and implies the imbalanced portion of classroom social atmosphere. The small number of students talk is as the least intention of every educational objectives stated for. It is, yet, a common scene from pure science class, particularly the mathematics subject where students are usually absorved in either working individually or in group to do assignment (17\%). Teacher took his role in explaining and giving example on the topics discussed, or correcting students' works. Interaction occured only when one or two students ask for confirmation or clarrification of the teacher. Class situation tent to be silent because the students were concentrating on their work.

Of the whole corpus on the five classroom interaction discussed, the bigger percentages of teacher's talk were in Physics (95\%) that took almost all talk in the classroom interaction. Only two significant situations represented in this class scene, they are 1) the situation of class was extremely silent as the teacher lecturing, and 2) the teacher used shopisticated media (OHP, nice Power point) in presenting the lesson. However, despite the use of interesting and nice visual aids displayed,the teacher was supposed to also activate and challenge the students to interact on the topics discussed. Yet, teacher was conportably and busily talk about the topic from his laptop, while students sleepily tried hard to pay attention. Students responded only when teacher asked simple questions.

Almost similar to Physics class, the English lesson also shows a dominance of teacher talk $(81 \%)$ in the whole verbal interaction during the teaching and learning process. Stu- dents shared only $19 \%$ of the total interaction. This scene could possibly understood for it was time for teacher to introduce a new topic, where he spent more time explaining and giving examples, and giving instruction to make sure that students could fully comprehend the lesson. This dialogical technique was generally successful to triger students initiate to talk and express their ideas confidently in maintaing the class discussion.

The IT/TIK, however, visualizes the most ideal atmosphere and social interaction of classroom, and significanlt contrast from the other four classrooms discussed. Almost no portion of teacher talk during the learning process, and only $6 \%$, if any, and it was almost no particular significant at all. Teacher opened the session by introducing the program and telling the class about the rules in doing group presentation, and the rest of it was then given to the class to manage. The students took almost all time (94\%), and seemed to be familiar with this method of learning, therefore they could manage themselve well, while teacher was attentively listened and took some notes for teacher's clarrification and resume used after the students presentation. Student started the presentation by explaining and elaborating the topic using power point, followed by question and answer session which was anthusiastically responded by the whole class.

They really devoted themselve to be actively participated in the discussion that represent their competence in communication, simple English but communicative enough to keep the discussion run well. The scene showed the real contectual and social interaction, so natural and interesting. It was a student and student interaction. And this is the mostly-wanted interaction intended by teachers and educators, and the best instance of simultanously achieving both paedagogic and communicative goals in teaching and learning process. Students were proudly showing their inisiative and participation in the discussed topic much more than it was expected by the teacher, that made her satisfied as well as inspired to be more sensitive in creating and planning her classes in the long run. The different approach in teaching tke lesson could, in fact, bring about a very different but positive effect on both the learning process and output toward the significant improvement.

\section{CONCLUSION AND SUGGESTION}

The Flanders Model (FIACS) analysis was mainly applied to the study of classroom interaction in the five classroom interaction proved to be teacher dominating the talk, however the one class, IT/TIK in contrast determined the most significant and inspiring model of teaching and learning process in the classroom. Of the five classes and subjects investigated, four of them showed the dominant role and talk of teachers as reference to the many traditional clasrooms claimed by researchers on their previous studies. It was in fact still in the same pattern of two-third (2/3) ratio of talking between teacher and students. The last scene was, however, very much different from the other four. When teacher wisely lent the role and democratically shared the responsible on the part of students, they would learn to be responsible learners, and teacher could play their potential role as facilitator and facilitator. 
Despite the potential of the FIACS analysis method, verbal interaction was found to be inadequate as a means of unraveling the complexities of socially shared learning processes.within peer groups from the perspective on interaction. Consequently, the analysis of verbal interaction alone seemed not to be sufficient anymore for the most part of the classroom interaction, particularly in the modern system of learning paradigms. It also seemed important that more attention be paid to the moment-by-moment nature of interaction in order to highlight the situated processes of meaning-making and knowledge construction within the individual and the group as units of analysis in order to deeply investigate the types and forms of participation within peer group presentation.

\section{REFERENCES}

Baker, C. (2003). Foundations of Bilingual Education and Bilingualism. Clevedon: Multilingual Matters.

Bialystok, E. (2001). Bilingualism in Development: Language, Literacy, and Cognition. Cambridge: Cambridge University Press.

Chin, C. (2006). Classroom Interaction in Science: Teacher Questioning and Feedback to Students Responses. International Journal of Science Education, 28(11).

Fisher, R. \& Larkin, D. (2007). Pedagogy or Ideology struggle? An Examination of Pupils' \& Teachers' Expectation for Talk in Classroom. Language and Education, 22(1).
Graddol, D. (1997). The Future of English. London: The British Council.

Imamullah, H.M., Uddin, M.N. \& Hussain, I. (2008). Teacher-Student Verbal Interaction Patterns at the Tertiary Level of Education. Contemporary Issues in Education Research, 1(1),45-50.

Kalu, I. (2003). Classroom Interaction Patterns \& Student's Learning Outcomes in Physic.

Meisuri. (2006). English as an Instructional Medium: It's Role in International and Bilingual Classes. Paper presented in the "International Education in Indonesia: Issues and Challenges" di UNIB, Bengkulu.

Meisuri. (2008). Internasionalisasi Pendidikan dan Pendidikan Keguruan: Revitalisasi Bahasa di Era Global. Paper, presented in The $3^{\text {th }}$ Seminar and Annual Meeting (Semirata) Wilayah Indonesia Barat in UNRI, Pekanbaru.

Meisuri. (2014). Pemrolehan Bahasa Inggris Sebagai Bahasa Kedua dalam Konteks Pendidikan Bilingual. Bahas, Vol. 40, No. 88, Januari-Maret. Medan: UNIMED Press.

Mejia, Anne-Marie de. 2002. Power, Prestige and Bilingualism: International Perspectives on Elite Bilingual Education. Clevedon: Multilingual Matters.

Mercer, N. (2010). The Analysis of Classroom Talk: Methods and Methodologies. British Journal of Educational, Vol. 80. Cambridge: Cambridge Univ. Press. (p. 1 - 14).

Zhi, E., \& Feng, L. (2013). An Analysis of Teacher-Student Interactions Patterns in a Robotics Course for Kindergarten Children: A Pilot Study. TOJET, 12(1). 